\title{
Glutathione Depletion, Lipid Peroxidation and Mitochondrial Dysfunction Are Induced by Chronic Stress in Rat Brain
}

José L. M. Madrigal, B.Sc., Raquel Olivenza, B.Sc., María A. Moro, Ph.D., Ignacio Lizasoain, M.D., Ph.D., Pedro Lorenzo, M.D., Ph.D., José Rodrigo, M.D., Ph.D., and Juan C. Leza, M.D., Ph.D.

Damage to the mitochondrial electron transport chain has been suggested to be an important factor in the pathogenesis of a range of neurodegenerative disorders. We have previously demonstrated that chronic stress induced an increase in nitric oxide (NO) production via an expression of inducible NO synthase (iNOS) in brain. Since it has been demonstrated that NO regulates mitochondrial function, we sought to study the susceptibility of the mitochondrial respiratory chain complexes to chronic restrain stress exposure in brain cortex. In adult male rats, stress (immobilization for six hours during 21 days) inhibits the activities of the first complexes of the mitochondrial respiratory chain (inhibition of $69 \%$ in complex I-III and of $67 \%$ in complex II-III), without affecting complex IV activity, ATP production and oxygen consumption. The mitochondrial marker citrate synthase is not significantly

KEY WORDS: Immobilization stress; Nitric oxide; Oxidative stress

In the last few years, several reports indicated that long lasting stress affects synaptic plasticity, dendritic morphology and neurogenesis in animals (rev. in Kim and Yoon 1998) and induces both clinical and anatomical fea-

From the Dpto. de Farmacología. Facultad de Medicina, Universidad Complutense (UCM) (JLMM, RO, MAM, IL, PL, JCL) and Instituto Cajal - Consejo Superior de Investigaciones Científicas (JR). Madrid. Spain.

Address correspondence to: Dr. Juan C Leza, Departamento de Farmacología, Universidad Complutense, Madrid 28040 Spain. Tel.: +34 91394 1478, Fax: +34 91394 1463, E-mail: jcleza@eucmax. sim.ucm

Received June 17, 2000; revised September 12, 2000; accepted September 19, 2000. affected by stress after 21 days, indicating that at this time the mitochondrial structure is still intact. Moreover, the administration of the preferred inducible nitric oxide synthase (iNOS) inhibitor aminoguanidine $(400 \mathrm{mg} / \mathrm{kg}$ i.p. daily from days 7 to 21 of stress) protects against the inhibition of the activity of complexes of the mitochondrial respiratory chain as well as prevents $\mathrm{NO}_{x}{ }^{-}$accumulation, lipid peroxidation and glutathione depletion induced by stress. These results suggest that a sustained overproduction of NO via iNOS is responsible, at least in part, of the inhibition of mitochondrial respiratory chain caused by stress and that this pathway also accounts for the oxidative stress found in this situation.

[Neuropsychopharmacology 24:420-429, 2001]

(C) 2001 American College of Neuropsychopharmacology. Published by Elsevier Science Inc.

tures of neurotoxic damage in humans (i.e. postraumatic stress disorder) (Sheline et al. 1996; Sapolsky 1996).

The precise mechanisms by which stress induces brain damage are still a matter of debate. The neurotoxic action of glutamate and other excitatory amino acids (EAA) mainly through $N$-methyl-D-aspartate (NMDA) receptor and the potentiation of their effects by glucocorticoids have been implicated in the pathogenesis of stress-induced brain injury (Sapolsky et al. 1990; Moghaddam 1993; Kim et al. 1996). Garthwaite et al. (1988) demonstrated that NMDA receptor activation generates nitric oxide (NO), and after this initial observation it was postulated that an overproduction of this molecule is the link between the actions of EAA and the subsequent cell damage (Dawson et al. 1991; Nowicki et 
al. 1991). In this context, not only constitutive formation of NO, but also inducible expression of iNOS has been found to occur in the brain during chronic stress (Leza et al. 1998; Olivenza et al. 2000).

It has been shown that free radicals such as $\mathrm{NO}$ and other oxygen-centered related species may damage a variety of cell macromolecules, including those which constitute the electron transport system, therefore disrupting mitochondrial function (Cleeter et al. 1994; Radi et al. 1994; Lizasoain et al. 1996; Bowling and Beal 1995).

Since mitochondrial dysfunction and oxidative damage play important roles in several neurodegenerative diseases (rev. in Bowling and Beal 1995), we sought to study whether repeated exposure to immobilization stress impairs these parameters in rat brain by using a stress paradigm which has been reported to cause neuronal damage (Magariños and McEwen 1995; Conrad et al. 1999) and to be useful in the study of neurobiological and behavioral consequences of traumatic stress (Telner and Singhal 1984; Bremner et al. 1991).

\section{MATERIALS AND METHODS}

\section{Animals}

Adult male Wistar rats weighing 225-250 g at the beginning of the experiment were used. All experimental protocols adhered to the guidelines of the Animal Welfare Committee of the Universidad Complutense. The rats were housed individually under standard conditions of temperature and humidity and a $12 \mathrm{~h}$ light/ dark cycle (lights on at $8 \mathrm{AM}$ ) with free access to food and water. All animals were maintained under constant conditions for four days prior to stress. Animals, food and water were weighed daily. Body weight and food ingestion was not significantly modified during the 21 days of repeated stress.

\section{Immobilization Stress}

Rats were exposed to stress between 9 AM and 3 PM in the animal homeroom. The immobilization was performed using a plastic rodent restrainer (Decapi-cone ${ }^{\circledR}$, Braintree) that allowed for a close fit to rats. The following restraint protocols were used six hours every day for 7, 14 or 21 days (S7, S14, S21) (Magariños and McEwen 1995). Control animals were housed in a different room, not subjected to stress, but were accustomed to handling. Animals were sacrificed immediately after the last session of immobilization (still in the restrainer) using sodium pentobarbital.

\section{Preparation of Submitochondrial Particles (SMP)}

Rat forebrain mitochondria were prepared by a modification of the method of Partridge et al. (1994). Animals were decapitated and brain cortices were rapidly removed and placed in ice-cold isolation buffer $(0.15 \mathrm{M}$ $\mathrm{KCl}, 20 \mathrm{mM}$ potassium phosphate, $\mathrm{pH}$ 7.6). The brain mitochondria were prepared by manual homogenization in a glass-glass homogenizer and centrifugation (17000 $\mathrm{g}$ for $10 \mathrm{~min})$ followed by a Ficoll gradient (10\% $\mathrm{w} / \mathrm{v}$ in isolation buffer) and ultracentrifugation $(100,000 \mathrm{~g}$ for $45 \mathrm{~min})$. The resultant pellet was resuspended in $3.5 \mathrm{ml}$ of isolation buffer and centrifuged at $9800 \mathrm{~g}$ for $10 \mathrm{~min}$ at $4^{\circ} \mathrm{C}$. A suspension of freshly prepared mitochondria was exposed to three cycles of freeze-thaw to obtain a high yield of SMP.

\section{Specific Activities of Mitochondrial Complexes}

All enzyme assays were performed at $37^{\circ} \mathrm{C}$ in a final volume of $1 \mathrm{ml}$, using a spectrophotometer (Beckman DU-7500). The activity of complex I-III (NADH-CoQ 1 reductase) was measured according to the method of Ragan et al. (1987) and of complex II-III (succinate-cytochrome $c$ reductase) according to the method of King (1967) in SMP samples with $1 \mathrm{mg} / \mathrm{ml}$ of mitochondrial protein. These enzyme activities were expressed as $\mathrm{nmol} / \mathrm{min}$ per $\mathrm{mg}$ of mitochondrial protein. The activity of cytochrome $c$ oxidase (complex IV) was measured according to the method of Wharton and Tzagoloff (1967), and expressed as $\mathrm{k} / \mathrm{min}$ per $\mathrm{mg}$ of mitochondrial protein, where $k$ is the first-order velocity constant $\left(k=2.3 \log \left(\mathrm{A}_{\left(\text {time }_{0}\right)}\right) / \mathrm{A}\left(\right.\right.$ time $\left.\left._{0}+1 \mathrm{~min}\right) \cdot \mathrm{min}^{-1}\right)$.

\section{Citrate Synthase Activity}

This activity was determined in SMP at a final protein concentration adjusted to $0.2 \mathrm{mg} / \mathrm{ml}$. This assay is based on the chemical coupling of CoA-SH released from Acetyl-CoA during the enzymatic synthesis of citrate to Ellman's reagent, 5,5'-dithio-bis-(2-nitrobenzoic) acid (Shepherd and Garland 1969; Robinson et al. 1987). The enzyme activity was measured using a Beckman DU-7500 spectrophotometer and expressed as $\mathrm{nmol} /$ min per mg of mitochondrial protein.

\section{Mitochondrial Respiration Measurements}

Freshly SMP samples were incubated (0.5 mg protein/ $\mathrm{ml}$ ) at $37^{\circ} \mathrm{C}$ with continuous stirring in $2 \mathrm{ml}$ buffer (50 $\mathrm{mM}$ potassium phosphate, $100 \mu \mathrm{M}$ EGTA, $\mathrm{pH}$ 7.2). NADH $(50 \mu \mathrm{M})$, succinate $(5 \mathrm{mM})$ or ascorbate $(5$ $\mathrm{mM}$ ) plus $N, N, N^{\prime}, N^{\prime}$-tetramethyl-p-phenylenediamine (TMPD, $0.5 \mathrm{mM}$ ) were used to quantify complex I-, II-, III- or IV-dependent respiration. SMP respiration was measured polarographically using a Clark-type oxygen micro-electrode (Model 5357, YSI Inc) (Lizasoain et al. 1996). 


\section{ATP Production}

The amount of ATP in forebrain samples was measured by using a commercial kit (Sigma). In short, ATP levels were determined in a Beckman DU-7500 spectrophotometer by measuring the decrease in absorbance at $340 \mathrm{~nm}$ that results when NADH is oxidized to NAD by the enzyme glyceraldehyde-3-phosphate dehydrogenase. The results were expressed as nmol per mg protein.

\section{Brain $\mathrm{NO}_{\mathrm{x}}{ }^{-}\left(\mathrm{NO}_{2}{ }^{-}\right.$and $\left.\mathrm{NO}_{3}{ }^{-}\right)$Levels}

NO production was estimated from the amounts of nitrite $\left(\mathrm{NO}_{2}{ }^{-}\right)$and nitrate $\left(\mathrm{NO}_{3}{ }^{-}\right)$in brain tissue. $\mathrm{NO}_{3}{ }^{-}$ was calculated by first reducing $\mathrm{NO}_{3}{ }^{-}$into $\mathrm{NO}_{2}{ }^{-}$in the presence of $\mathrm{Cd}$ (Cortas and Wakid 1990) and $\mathrm{NO}_{2}{ }^{-}$was determined by a colorimetric assay based on the Griess reaction (Green et al. 1982) in a Thermomax ${ }^{\circledR}$ microplate reader (Molecular Devices). The measurement of $\mathrm{NO}_{x}{ }^{-}$levels has been found to be a reliable technique to determine the synthesizing capacity of NOS in brain (Salter et al. 1996).

\section{Characterization of iNOS by Western Blot}

Tissues were homogenized as described (Olivenza et al. 2000), and after centrifugation in a microcentrifuge for $15 \mathrm{~min}$, the proteins present in the supernatant were loaded $(10 \mu \mathrm{g})$ and size-separated in 10\% SDS-polyacrilamide gel electrophoresis $(90 \mathrm{~mA})$. The gels were processed against the Ags and after blotting onto a polyvinylidene difluoride membrane (Millipore, Bedford, MA, USA) were incubated with a specific polyclonal iNOS antibody (Santa Cruz Biotechnology, Santa Cruz, CA, USA; 1:1000 dilution). Proteins recognized by the antibody were revealed by ECL technique following manufacturer's instructions (Amersham Ibérica, Madrid, Spain).

\section{Immunohistochemistry}

Rats were anesthetized with sodium pentobarbital and perfused through the left ventricle with $200 \mathrm{ml}$ of saline as a vascular rinse followed by $500 \mathrm{ml}$ of fixative solution containing $4 \%$ paraformaldehyde in $0.1 \mathrm{M}$ sodium phosphate buffer (PB), $\mathrm{pH}$ 7.4. The brains were removed, postfixed for three hours in the same solution of paraformaldehyde at room temperature, and then cryoprotected by immersion overnight at $4^{\circ} \mathrm{C}$ in $0.1 \mathrm{M}$ PB containing $30 \%$ sucrose.

Brains were frozen and serial $40-\mu \mathrm{m}$-thick frontal sections were cut with a Leitz sledge microtome. Freefloating sections of the whole brain were incubated with specific antiserum and processed by the avidinbiotin peroxidase complex (ABC) procedure (Guesdon et al. 1978; Hsu and Raine 1981; Rodrigo et al. 1994) to visualize immunoreactive sites for iNOS and for nitrotyrosine, a nitration product of peroxynitrite. All the free-floating sections were incubated for 30 min in phosphate-buffered saline (PBS) containing 3\% normal goat serum (ICN Biochemicals, Barcelona, Spain) and $0.2 \%$ Triton X-100, and then in iNOS diluted 1:2500 (Santa Cruz Biotechnology, Santa Cruz, CA, USA) or in anti-nitrotyrosine diluted 1:1000 (Uttenthal et al. 1998) in PBS/triton X-100 overnight at $4^{\circ} \mathrm{C}$. After several washes in PBS, the sections were incubated with biotinylated goat anti-rabbit immunoglobulin for one hour. After washing, the sections were incubated with peroxidase-linked $A B C$ (Vector Laboratories, Burlingame, CA, USA) for $90 \mathrm{~min}$. The peroxidase activity was demonstrated by the nickelenhanced diaminobenzidine procedure (Shu et al. 1988).

\section{Lipid Peroxidation}

Lipid peroxidation was measured by the thiobarbituric acid test for malondialdehyde following the method described by Das and Ratty (1987) and modified by Colado et al. (1997). Half forebrain was homogenized in 10 vols $50 \mathrm{mM}$ phosphate buffer and deproteinized with $40 \%$ trichloroacetic acid (TCA), and $5 \mathrm{M} \mathrm{HCl}$, followed by the addition of $2 \%(\mathrm{w} / \mathrm{v})$ thiobarbituric acid in $0.5 \mathrm{M}$ $\mathrm{NaOH}$. The reaction mixture was heated in a water bath at $90^{\circ} \mathrm{C}$ for 15 minutes and centrifuged at $12000 \mathrm{~g}$ for 10 $\mathrm{min}$. The pink chromogen was measured at $532 \mathrm{~nm}$ in a Beckman DU-7500 spectrophotometer. The results were expressed as $\mathrm{nM}$ per $\mathrm{mg}$ of protein basis.

\section{Brain Glutathione Levels}

Brain glutathione levels were measured as previously described (Anderson 1985). Half forebrain was removed from the skull and frozen in ethanol. After that, tissues were rinsed in water and homogenized in 5\% $\mathrm{w} / \mathrm{v} 5$-sulfosalycilic acid and centrifuged at $4500 \mathrm{~g}$ for five minutes. The supernatants were stored at $4^{\circ} \mathrm{C}$ until assayed. This supernatant is oxidized by $6 \mathrm{mM} \mathrm{5,5^{ \prime } -}$ dithio-bis-(2-nitrobenzoic) acid (DTNB) to give reduced glutathione (GSSG) with stoichiometric formation of 5-thio-2-nitrobenzoic acid (TNB). GSSG is reduced to glutathione $(\mathrm{GSH})$ by the addition of highly specific glutathione reductase $(266 \mathrm{U} / \mathrm{ml}$ from stock enzyme with $143 \mathrm{mM}$ sodium phosophate and $6.3 \mathrm{mM} \mathrm{Na}_{4}$-EDTA at $\mathrm{pH}$ 7.5) and 0.3M NADPH. The rate of TNB formation is measured at $412 \mathrm{~nm}$ in a Beckman DU-7500 spectrophotometer and is proportional to the sum of GSH 
and GSSG present. Results were expressed as nmol GSH / min per g tissue.

\section{Treatment}

A group of six animals were treated with aminoguanidine at doses ( $400 \mathrm{mg} / \mathrm{kg}$ i.p.) sufficient to achieve an in vivo inhibition of iNOS (Southan and Szabo 1996) for 14 days (days 7 to 21).

\section{Protein Assay}

Proteins were measured using bicinchoninic acid (Hill and Straka 1988).

\section{Chemicals and Statistical Analyses}

Unless otherwise stated, the chemicals used were from Sigma (Madrid, Spain). Results are expressed as mean \pm SEM of the indicated number of experiments; statistical comparisons were made using a Newman-Keuls test and $p<.05$ was considered as statistically significant.

\section{RESULTS}

\section{Effects of Stress on Mitochondrial Enzymatic Activities}

As shown in Figure 1, mitochondrial complex I-III activity was significantly decreased as early as seven days of repeated exposure to restrain stress. Complex II-III activity decreased after two weeks of stress exposure (Figure 1). However, long-term stress did not significantly alter the specific activity of complex IV (Figure 1). The activity of the mitochondrial marker citrate synthase was not affected by stress (14 days of stress -S14-: $5.6 \pm 0.8 ; 21$ days of stress -S21-: $6.5 \pm 1.3, p>.05$ vs. control: $6.3 \pm 1.4 \mathrm{pmol} / \mathrm{min}$ per mg protein).

In spite of the stress-induced decrease in enzymatic activity of the first complexes of the mitochondrial chain, there were no differences in oxygen consumption by the three complexes studied (complex I/III control: $16.04 \pm 1.92 \mu \mathrm{M} \mathrm{O}_{2} / \mathrm{min}$; S21: $94.3 \pm 18.0 \%$ of control; complex II/III control: $18.64 \pm 2.89 \mu \mathrm{M} \mathrm{O}_{2} /$ min; S21: $82.0 \pm 11.3 \%$ of control; complex IV control: $23.73 \pm 3.16 \mu \mathrm{M} \mathrm{O}_{2} / \mathrm{min}$; $21: 89.6 \pm 15.1 \%$ of control, all $p>.05, \mathrm{n}=6-8)$. Similarly, there were no differ-
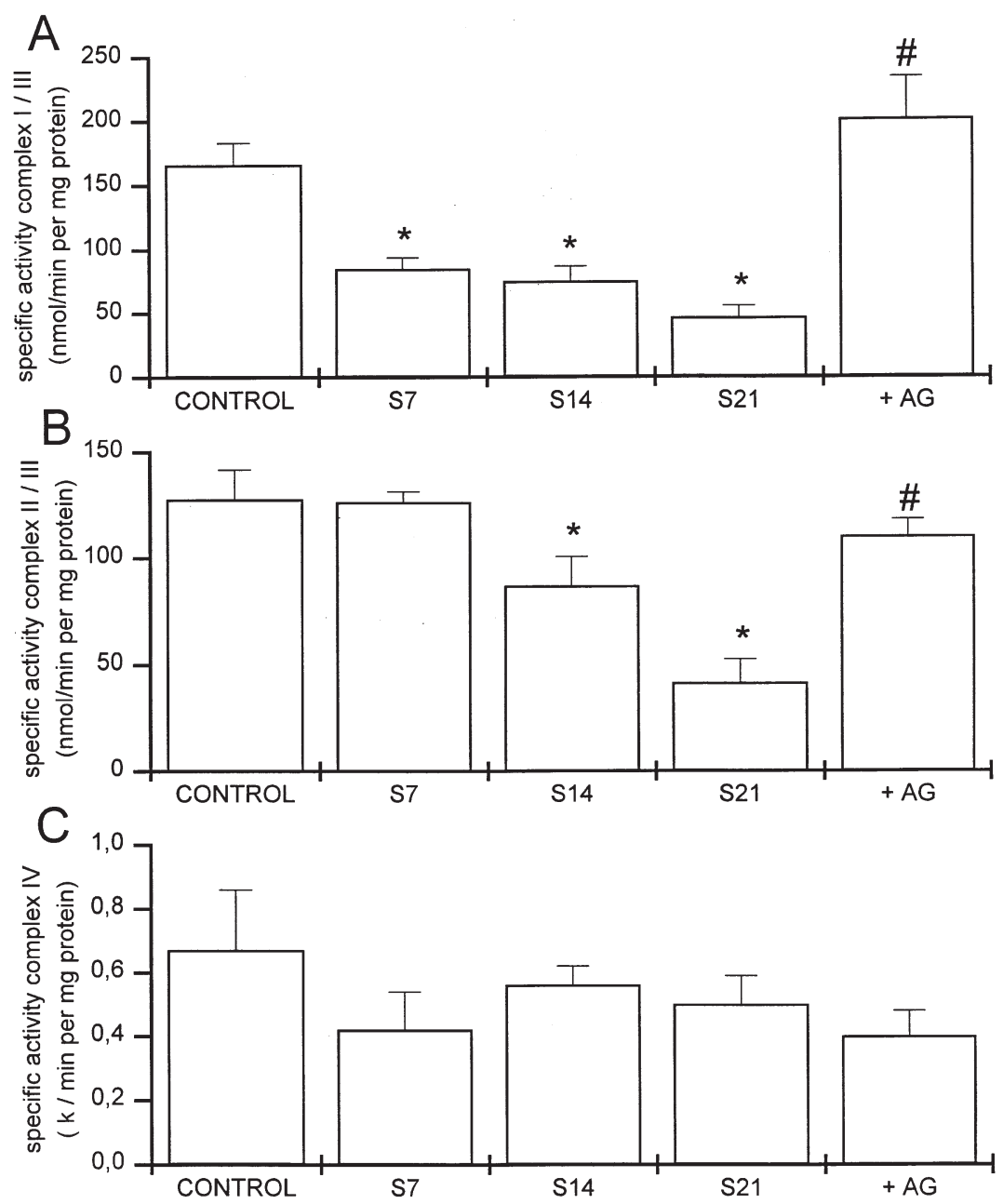

Figure 1. Effect of repeated restraint stress (immobilization during 7, 14 or 21 days -S7, S14, S21-) on the activities of mitochondrial respiratory chain complexes. Effect of aminoguanidine (AG) administered (400 $\mathrm{mg} / \mathrm{kg}$ ip daily) to stressed rats. Panel A: complex I/III; Panel B: complex II/III; Panel C: complex IV (see MATERIALS AND METHODS). Data are mean \pm SEM values of 6-8 rats and are expressed as nmol/ $\mathrm{min} / \mathrm{mg}$ of mitochondrial protein, except for complex IV activity, which is expressed as $\mathrm{k} / \mathrm{min} / \mathrm{mg}$ of mitochondrial protein, where $k$ is the first-order rate constant. ${ }^{*} p<$ .05 vs. control, \# $p<.05$ vs. S21 (NewmanKeuls test). 
ences in brain ATP production in control: $0.9 \pm 0.2$ vs. 21 days stressed rats: $1.3 \pm 0.2 \mathrm{nmol} / \mathrm{min}$ per mg protein, $p>.05(\mathrm{n}=6)$.

\section{Effects of an iNOS Inhibitor on Stress-Induced Mitochondrial Impairment}

In view of the impairment of the activity of mitochondrial complexes, we studied the possible role of $\mathrm{NO}$ in mitochondrial deficiency caused by prolonged stress exposure. Exposure to stress produced an accumulation of $\mathrm{NO}$ metabolites $-\mathrm{NO}_{2}{ }^{-}$and $\mathrm{NO}_{3}{ }^{-}$- in brain tissue in our model (Figure 2), as well as the expression of iNOS protein in cortex (Figure 3) and the appearance of different immunoreactive cortical structures after 21 days of immobilization (Figure 3). iNOS immunoreactive cells with a neuronal morphology of pyramidal and fusiform cells were found in layers II to VI of the cortex. Nitrotyrosine immunoreactive cells were also found at 21 days of stress in various cortical areas with morphology of pyramidal cells (Figure 3). No immunostaining was found in sections taken from brains of control animals (data not shown). A more detailed explanation of the morphological changes based in immunohistochemical studies has been recently published (Olivenza et al. 2000).

Treatment with the preferred iNOS inhibitor aminoguanidine ( $400 \mathrm{mg} / \mathrm{kg}$ ip daily) prevented the accumulation of $\mathrm{NO}_{x}{ }^{-}$(Figure 2), as well as the decreases in complexes I-III and II-III induced by long-term exposure to stress (Figure 1).

\section{Effects of Stress on Oxidative/Nitrosative Markers. Effect of Aminoguanidine}

The previously described accumulation of NO metabolites in brain cortex induced by stress was paralleled by an increase in lipid peroxidation, as demonstrated by the accumulation of the aldehydic product of lipid peroxidation malondialdehyde (MDA) levels in brain tissue that we have found in this particular experimental model $(166 \%$ of control levels after 21 days of stress, Figure 4). We also studied the cellular antioxidant status by measuring the levels of glutathione. We have found that stress (S21) decreases brain GSH levels by $36.7 \%$ as compared with control rats (Figure 5).

Pharmacological inhibition of iNOS with aminoguanidine prevented the accumulation of MDA (Figure 4) and GSH depletion found after 21 days of stress (Figure 5).

\section{DISCUSSION}

We have studied the susceptibility of the mitochondrial respiratory chain complexes in rat brain exposed to a chronic restrain stress paradigm. Our results reveal that NO produced in this condition gives rise to a marked

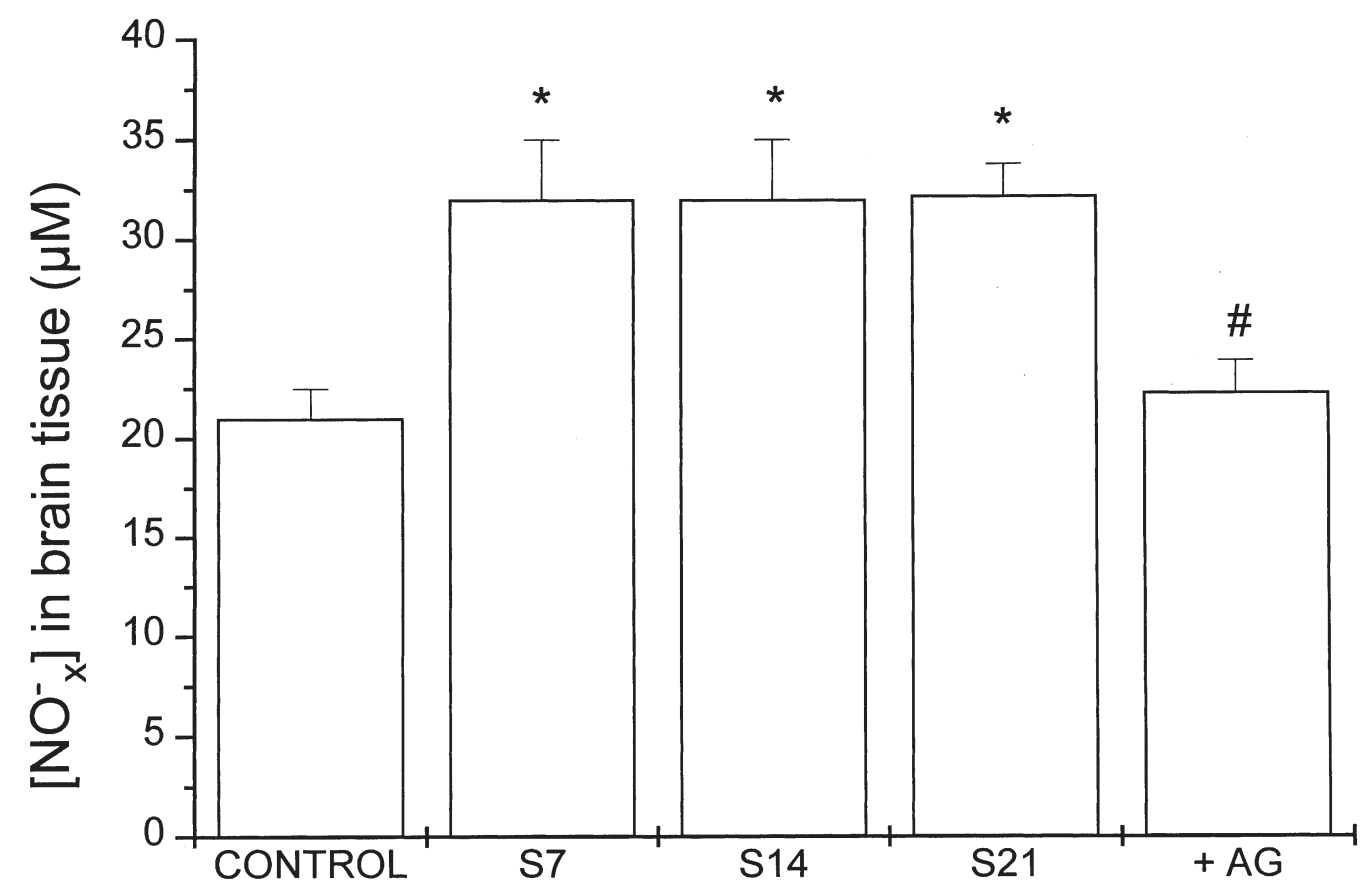

Figure 2. Effect of immobilization exposure on $\mathrm{NO}_{2}{ }^{-}$and $\mathrm{NO}_{3}{ }^{-}\left(\mathrm{NO}_{\mathrm{x}}{ }^{-}\right)$levels in brain cortex of control and stressed rats for 7, 14 and 21 days (S7, S14, S21) and 21 days-stressed rats receiving a daily dose of $400 \mathrm{mg} / \mathrm{kg}$ i.p. of aminoguanidine (AG). The data represent the means \pm S.E.M. of six rats. ${ }^{*} p<.05$ vs. control, \# $p<.05$ vs. S21 (Newman-Keuls test). 
A)

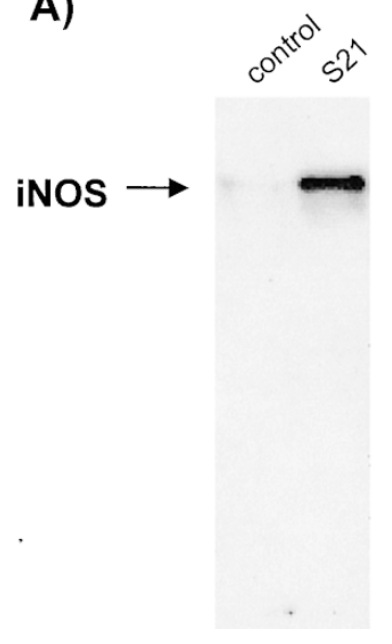

B)
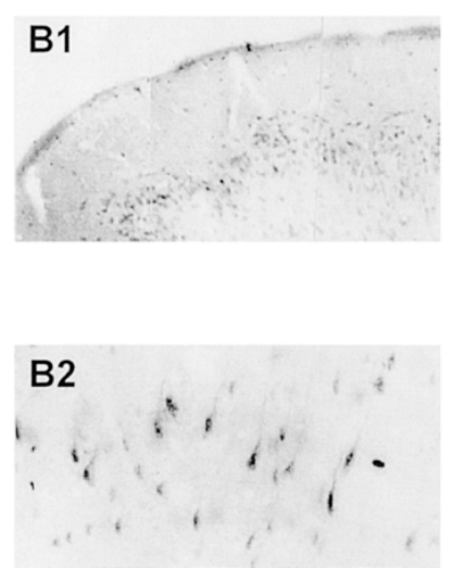

C)
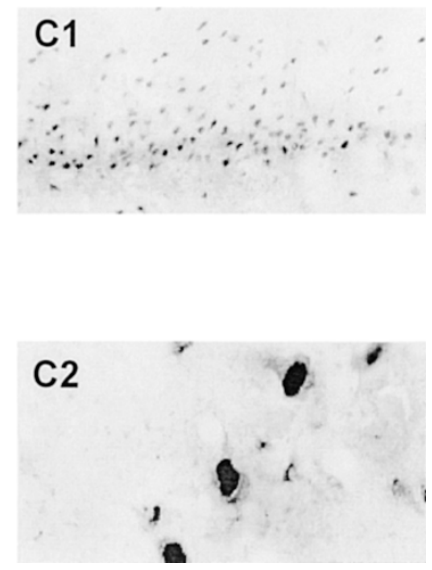

Figure 3. Detection of iNOS protein by Western blot (Panel A) in cortex homogenates in control rats and rats exposed to restrain stress for 21 days (S21). Inducible nitric oxide synthase staining (Panel B) and nitrotyrosine staining (Panel C) of neuronal cells in cortical sections after 21 days of repeated immobilization stress. Scale bar: B1,C1 (1:0.05); B2,C2 (1:0.01).

inhibition of the first complexes of the mitochondrial respiratory chain. The deleterious effects of stress on mitochondrial functioning appear to be sequential and cumulative, affecting primarily-after seven days-to complex I and afterwards-14 days-to complex II. In this work we have used a classical stress paradigm for three weeks, used by others to describe specific neuronal damage induced by stress (Magariños and Mc-
Ewen 1995; Conrad et al. 1996; Magariños et al. 1997; Conrad et al. 1999).

The mitochondrial marker citrate synthase activity was not significantly affected by stress, indicating that at this time of repeated stress the mitochondrial structure was still intact, with no leakage of mitochondrial matrix components. Magariños et al. (1997), using the same model that we used here, found that stress did not

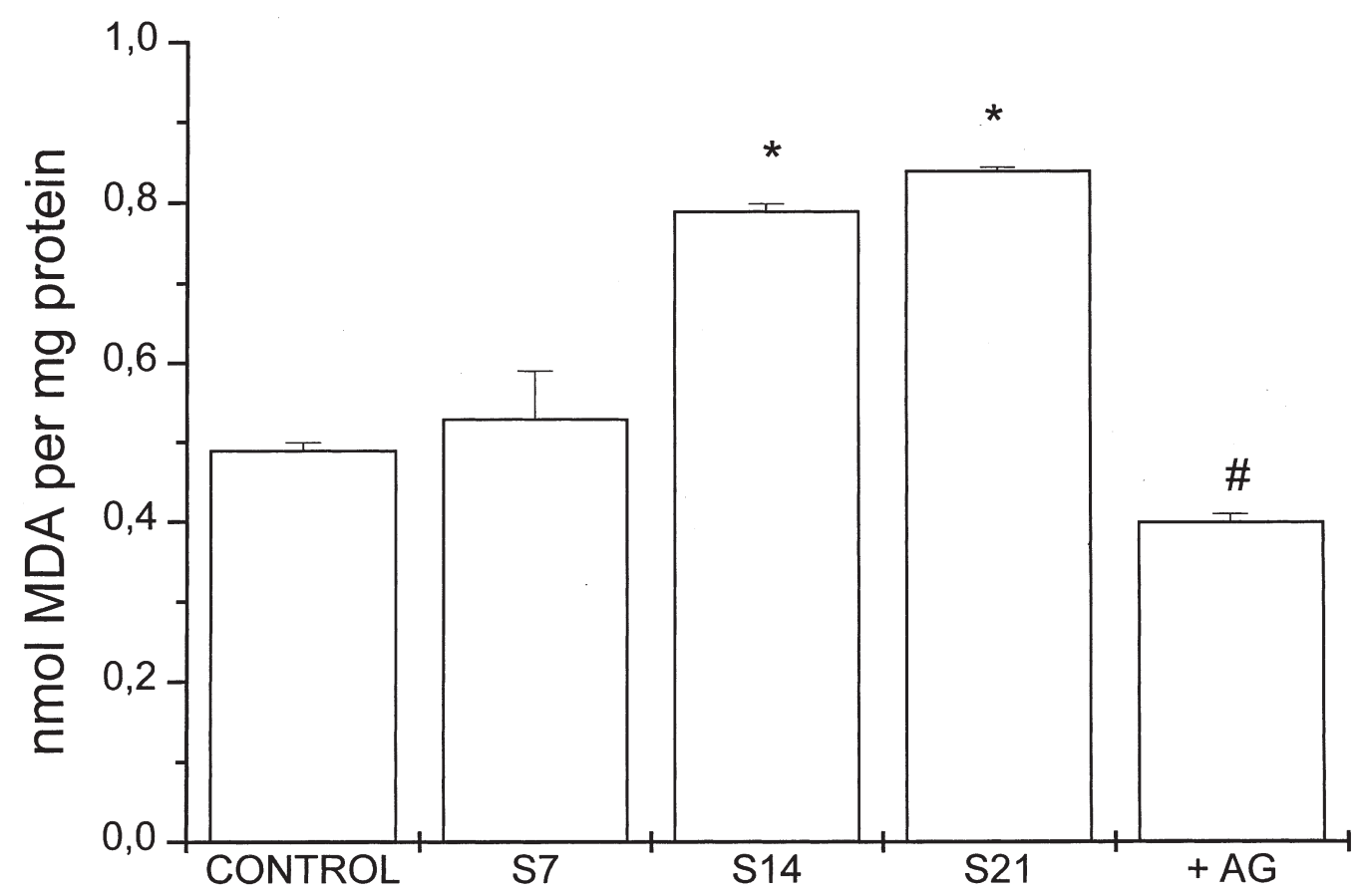

Figure 4. Effect of immobilization exposure on malondialdehyde (MDA) levels in brain cortex of control and stressed rats for 7, 14 and 21 days (S7, S14, S21) and 21 days-stressed rats receiving a daily dose of $400 \mathrm{mg} / \mathrm{kg}$ i.p. of aminoguanidine (AG). The data represent the means \pm S.E.M. of six rats. ${ }^{*} p<.05$ vs. control; \# $p<.05$ vs. S21 (Newman-Keuls test). 


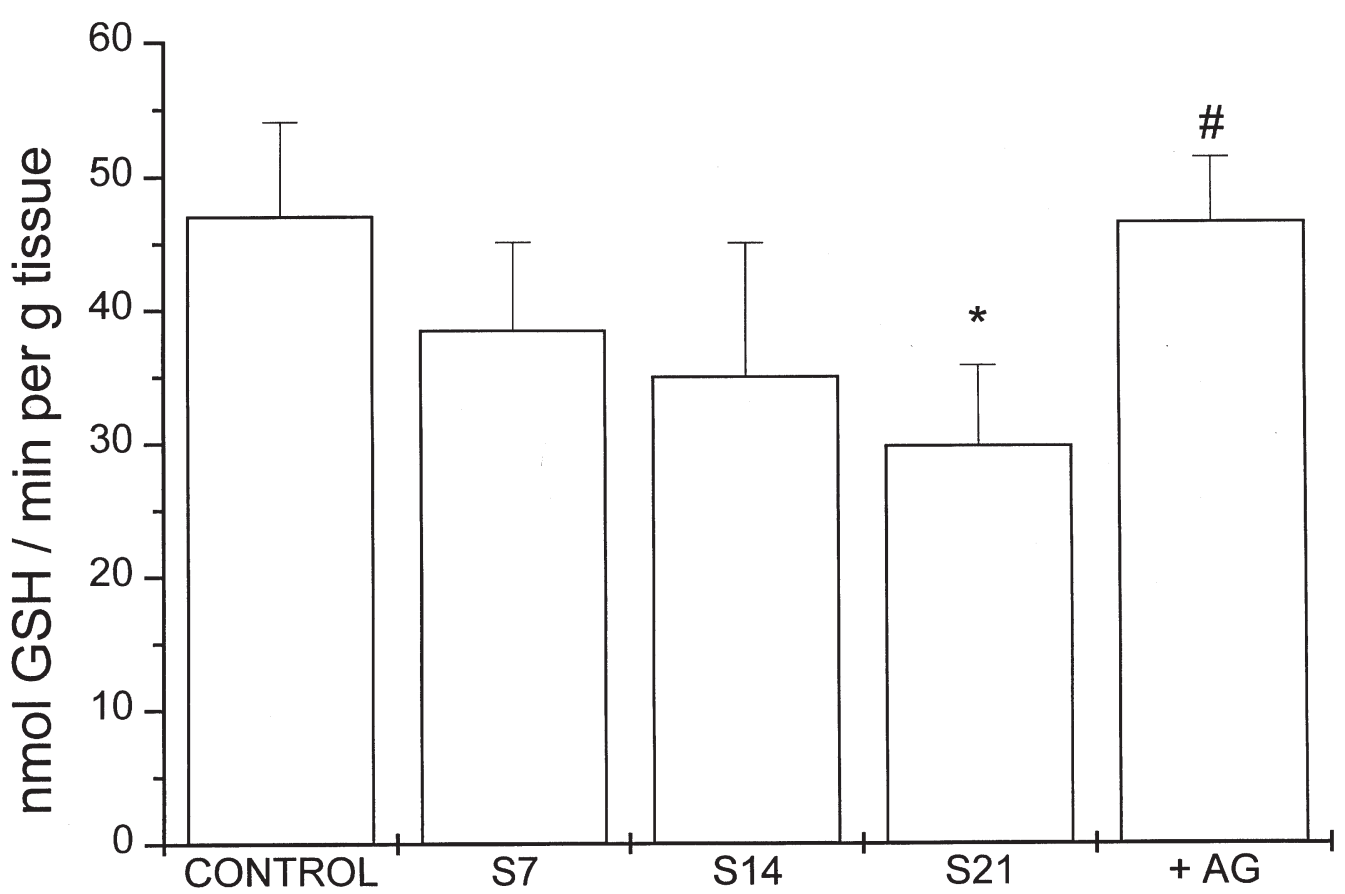

Figure 5. Effect of immobilization exposure on glutathione (GSH) levels in brain cortex of control and stressed rats for 7, 14 and 21 days (S7, S14, S21) and 21 days-stressed rats receiving a daily dose of $400 \mathrm{mg} / \mathrm{kg}$ i.p. of aminoguanidine (AG). The data represent the means \pm S.E.M. of six rats. ${ }^{*} p<.05$ vs. control; \# $p<.05$ vs. S21 (Newman-Keuls test).

affect the number of neuronal mitochondria; however, the total area occupied by mitochondria increased slightly after the stress paradigm. Although this has not been demonstrated, it suggests that a longer duration of stress could compromise ATP synthesis.

Recent reports indicate that the overall capability of mitochondria to maintain energy homeostasis might not be affected unless a certain threshold of decreased complex activity has been reached (Davey and Clark 1996). According to this study, complex I and complex III activities could be decreased by $72 \%$ and $70 \%$ respectively before major changes in mitochondrial respiration and ATP synthesis took place. In agreement with this, inhibition of $69 \%$ in complex I-III and $67 \%$ in complex II-III activities that we have found in our model did not alter oxygen consumption or ATP production. Such decreases are theoretically in the limit of brain mitochondria to face this kind of stressful stimulus. These findings are in agreement with previous reports indicating that 21 days of repeated stress causes neuronal damage that reverts to baseline after 7-10 days (Conrad et al. 1999)

It is well known that mitochondrial oxidative phosphorylation system generates free radicals (rev. in Forman and Azzi 1997) and the electron transport chain itself is vulnerable to damage by free radicals (rev. in Bowling and Beal 1995). Therefore, the oxidative damage induced by stress may be either the cause or the consequence of the mitochondrial dysfunction. The reported increase in brain NO production by stress-induced iNOS expression (Olivenza et al. 2000) is likely to inhibit reversibly mitochondrial respiration as it has been reported to occur in brain mitochondria (Lizasoain et al. 1996). Interestingly, superoxide $\left(\mathrm{O}_{2}^{-}\right)_{-}$-a by-product of mitochondrial respiratory chain-increases in the presence of inhibitors as NO (Poderoso et al. 1996). Thus, a sustained production of $\mathrm{NO}$, together with this resulting formation of $\mathrm{O}^{-}{ }_{2}$ may, because of formation of peroxynitrite $\left(\mathrm{ONOO}^{-}\right)$within the mitochondria, likely be cause of the irreversible inhibition of complexes I-III and II-III (Lizasoain et al. 1996) that we have found.

This sustained mitochondrial inhibition would potentiate $\mathrm{ONOO}^{-}$formation, leading to the depletion of antioxidant defenses (thiols such as GSH) (Radi et al. 1991b) and initiation of lipid peroxidation (Radi et al. 1991a; Darley-Usmar et al. 1992). Lipid peroxidation could cause structural damage to membranes, including those which form mitochondria, and potentiate their dysfunction.

On the other hand, an initial formation of large amounts of oxygen and nitrogen reactive species during stress may also initiate lipid peroxidation (Braughler and Hall 1989) as it has been demonstrated to occur in brain (Liu et al. 1996) liver and heart (Hu et al. 2000). Since the complexes are membrane-bound and sensitive to the lipid microenvironment (Fry and Green 1980; 
Keller et al. 1997), oxidative damage to the inner mitochondrial membrane may also be involved in mitochondrial impairment. In addition, an increase in lipid peroxidation may be also due to an insufficiency of the protective antioxidant systems (mainly GSH), which are also depleted by $\mathrm{ONOO}^{-}$(Radi et al. 1991b). Thus, the decrease in brain GSH ( 37\%) that occurs after chronic stress exposure could be of great importance in the decrease in mitochondrial respiratory chain complex activity reported here, and confirms their sensitivity to cellular antioxidant status (Bolaños et al. 1996).

Besides causing cell membrane damage, lipid peroxidation has been also shown to be involved in excitotoxicity by several mechanisms, including a sequence of events that involves decreased ATP levels, reduced $\mathrm{Na}^{+}, \mathrm{K}^{+}$-ATPase, relief of the voltage-dependent $\mathrm{Mg}^{2+}$ block of NMDA associated channels and damage of glutamate transporters (Keller et al. 1997; Mark et al. 1997). This can be, at least in part, one of the mechanisms of the reported decrease in glutamate uptake after stress exposure (Leza et al. 1998; Olivenza et al. 2000).

Such accumulation of NO and the possibility of synthesis of related species during stress is likely to be due to a powerful source as the high output inducible NOS isoform as we have demonstrated. The finding of the effects of aminoguanidine preventing the inhibition of the activity of the mitochondrial respiratory chain, the increase on MDA, the depletion on GSH and the accumulation of $\mathrm{NO}_{\mathrm{x}}{ }^{-}$, strongly suggests that this NOS isoform is involved in tissue damage in this particular experimental model. In addition, we cannot discard that a certain contribution to these findings may result from direct antioxidant effects of aminoguanidine. The mechanisms of iNOS induction during stress remains to be elucidated, but it has been shown that several iNOS inductors such as cytokines are released in brain of stressed animals (Shintani et al. 1995). On the other hand, stress-induced glutamate release might be involved in iNOS expression, similarly to what we have found in rat forebrain slices exposed to oxygen-glucose deprivation (Cárdenas et al. 2000).

In conclusion, the results of this study suggest that a sustained overproduction of NO via iNOS is responsible, at least in part, of some of the deleterious effects caused by stress in brain mitochondria. Further studies should determine whether specific inhibition of iNOS would be of therapeutic benefit in this condition of vast overproduction of NO.

\section{ACKNOWLEDGMENTS}

Supported by DGES 97/0054, UCM 6784 181/96 and Fundación Central Hispano. RO was a recipient of a FPI fellowship of the Ministry of Education and Culture, Spain.

\section{REFERENCES}

Anderson M (1985): Determination of glutathione and glutathione disulfide in biological samples. Meth Enzymol 113:548-555

Bolaños JP, Heales SJR, Peuchen S, Barker JE, Land JM, Clark JB (1996): Nitric oxide-mediated mitochondrial damage: a potential neuroprotective role for glutathione. Free Rad Biol Med 21:995-1001

Bowling AC, Beal MF (1995): Bioenergetic and oxidative stress in neurodegenerative diseases. Life Sci 56:11511171

Braughler JM, Hall ED (1989): Central nervous system trauma and stroke. I. Biochemical considerations for free radical dormation and lipid peroxidation. Free Rad Biol Med 6:289-301

Bremner JD, Southwick SM, Charney DS (1991): Animal models for the neurobiology of trauma. PTSD Res Quart $2: 1-7$

Cárdenas A, Moro MA, Hurtado O, Leza JC, Lorenzo P, Castrillo A, Bodelón OG, Boscá L, Lizasoain I (2000): Implication of glutamate in the expression of inducible nitric oxide synthase after oxygen and glucose deprivation in rat forebrain slices. J Neurochem 74:2041-2048

Cleeter MWJ, Cooper JM, Darley-Usmar VM, Moncada S, Schapira AHV (1994): Reversible inhibition of cytochrome c oxidase, the terminal enzyme of the mitochondrial respiratory chain, by nitric oxide. Implications for neurodegenerative diseases. FEBS Lett 345:50-54

Colado MI, O'Shea E, Granados R, Misra A, Murray TK, Green AR (1997): A study of the neurotoxic effect of MDMA ("ectasy") on 5-HT neurones in the brains of mothers and neonates following administration of the drug during pregnancy. Br J. Pharmacol 121:827-33

Conrad CD, Galea LA, Kuroda Y, McEwen BS (1996): Chronic stress impairs rat spatial memory on the $Y$ maze, and this effect is blocked by tianeptine pretreatment. Behav Neurosci 110:1321-1334

Conrad CD, LeDoux JE, Magariños AM, McEwen BS (1999): Repeated restraint stress facilitates fear conditioning independently of causing hippocampal CA3 dendritic atrophy. Behav Neurosci 113:902-913

Cortas NK, Wakid NW (1990): Determination of inorganic nitrate in serum and urine by a kinetic cadmium-reduction method. Clin Chem 36:1440-1443

Darley-Usmar VM, Hogg H, O'Learly VJ, Wilson MT, Moncada S (1992): The simultaneous generation of superoxide and nitric oxide can initiate lipid peroxidation in human low density lipoprotein. Free Rad Res Commun 17:9-20

Das NP, Ratty AK (1987): Studies on the effects of the narcotic alkaloids, cocaine, morphine and codeine on nonenzymatic lipid peroxidation in rat brain mitochondria. Biochem Med Metab Biol 37:256-264

Davey GP, Clark JB (1996): Threshold effects and control of oxidative phosphorilation in nonsynaptic rat brain mitochondria. J Neurochem 66:1617-1624

Dawson VL, Dawson TM, London ED, Bredt DS, Snyder SH (1991): Nitric oxide mediates glutamate neurotoxicity in primary cortical cultures. Proc Natl Acad Sci USA 88:6368-6371 
Forman HJ, Azzi A (1997): On the virtual existence of superoxide anions in mitochondria: thoughts regarding its role in pathophysiology. FASEB J 11:374-375

Fry M, Green DE (1980): Cardiolipin requirement by cytochrome c oxidase and the catalytic role of phospholipid. Biochem Biophys Res Commun 93:1238-1246

Garthwaite J, Charles SL, Chess-Williams R (1988): Endothelium-derived relaxing factor release on activation of NMDA receptors suggests role as intercellular messenger in the brain. Nature 336:385-388

Green LC, Wagner DA, Glogowski J, Skipper PL, Whishnok JS, Tannenbaum SR (1982): Analysis of nitrate, nitrite and $\left[{ }^{15} \mathrm{~N}\right]$ in biological fluids. Anal Biochem 126:131-138

Guesdon JL, Ternyck J, Avrameas S (1978): The use of avidin-biotin interaction in immunoenzymatic techniques. J Histochem Cytochem 27:1131-1139

Hill HD, Straka JG (1988): Protein determination using bicinchoninic acid in the presence of sulfhydryl reagents. Anal Biochem 170:203-208

Hsu SM, Raine L (1981): Protein A, avidin and biotin in immunocytochemistry. J Histochem. 79:1349-1353

Hu Y, Cardounel A, Gursoy E, Anderson P, Kalimi M (2000): Anti-stress effects of dehydroepiandrosterone. Protection of rats against repeated immobilization stressinduced weight loss, glucocorticoid receptor production, and lipid peroxidation. Biochem Pharmacol 59:753-762

Keller JN, Mark RJ, Bruce AJ, Blanc E, Rothstein JD, Uchida K, Waeg G, Mattson MP (1997): 4-Hydroxynonenal, an aldehydic product of membrane lipid peroxidation, impairs glutamate transport and mitochondrial function in synaptosomes. Neuroscience 80:685-696

Kim JJ, Foy MR, Thompson RF (1996): Behavioral stress modifies hippocampal plasticity through $N$-methyl-Daspartate receptor activation. Proc Natl Acad Sci USA 93:4750-4753

Kim JJ, Yoon KS (1998): Stress: metaplastic effects in the hippocampus. Trends Neurosci 21:505-509

King T.E. (1967): Preparation of succinate cytochrome c reductase and the cytochrome b-c1 particle, and reconstitution of succinate cytochrome c reductase. Methods Enzymol 10:216-225

Leza JC, Salas E, Sawicki G, Russell JC, Radomski MW (1998): The effect of stress on homeostasis in JCR:LA-cp rats: the role of nitric oxide. J Pharmacol Exp Ther 286:1397-1403

Liu J, Wang X, Shigenaga MK, Yeo HC, Mori A, Ames BS (1996): Immobilization stress causes oxidative damage to lipid, protein and DNA in the brain of rats. FASEB J 10:1532-1538

Lizasoain I, Moro MA, Knowles RK, Darley-Usmar V, Moncada S (1996): Nitric oxide and peroxynitrite exert distinct effects on mitochondrial respiration which are differentially blocked by glutathione or glucose. Biochem J 314:877-880

Magariños AM, García Verdugo JM, McEwen BS (1997): Chronic stress alters synaptic terminal structure in hippocampus. Proc Natl Acad Sci USA 94:14002-14008

Magariños AM, McEwen BS (1995): Stress-induced atrophy of apical dendrites of hippocampal CA3c neurons: comparisons of stressors. Neuroscience 69:83-88

Mark RJ, Lovell MA, Markesbery WR, Uchida K, Mattson MP (1997): A role for 4-hydroxynonenal, an aldehydic product of lipid peroxidation, in disruption of ion homeostasis and neuronal death induced by amyloid amiloid beta-peptide. J Neurochem 68:255-264

Moghaddam B. (1993): Stress preferentially increases extraneuronal levels of excitatory amino acids in the prefrontal cortex: comparison to hippocampus and basal ganglia. J Neurochem 60:1650-1657

Nowicki JP, Duval D, Poignet H, Scatton B (1991): Nitric oxide mediates neuronal death after focal cerebral ischaemia in the mouse. Eur J Pharmacol 204:339-340

Olivenza R, Moro MA, Lizasoain L, Lorenzo P, Fernández AP, Rodrigo J, Boscá L, and Leza JC (2000): Chronic stress induces the expression of inducible nitric oxide synthase in rat brain cortex. J Neurochem 74:785-791

Partridge RS, Monroe SM, Parks JK, Johnson K, Parker WD, Eaton GR, Eaton SS (1994): Spin trapping of azidyl and hydroxyl radicals in azide-inhibited rat brain submitochondrial particles. Arch Biochem Biophys 310:210-217

Poderoso JJ, Carreras MC, Lisdero C, Riobo N, Schopfer F, Boveris A (1996): Nitric oxide inhibits electron transfer and increases superoxide radical production in rat heart mitochondria and submitochondrial particles. Arch Biochem Biophys 328:85-92

Radi R, Beckman JS, Bush KM, Freeman BA (1991a): Peroxynitrite-induced membrane lipid peroxidation: the cytocoxic potential of superoxide and nitric oxide. Arch Biochem Biophys 288:481-487

Radi R, Beckman JS, Bush KM, Freeman BA (1991b): Peroxynitrite oxidation of sulfhydryls. The citotoxic potential of superoxide and nitric oxide. J Biol Chem 266:42444250

Radi R, Rodríguez M, Castro L, Telleri R (1994): Inhibition of mitochondrial electron transport by peroxynitrite. Arch Biochem Biophys 308:89-95

Ragan CI, Wilson MT, Darley-Usmar VM, Lowe PN (1987): Subfractionation of mitochondria an isolation of the proteins of oxidative phosphorilation. In Darley-Usmar VM, Rickwood D, Wilson MT (eds), Mitochondria: a practical approach. London, IRL Press, pp 79-112

Robinson JB, Brent LG, Sumegi B, Srere PA (1987): An enzymatic approach to the study of the Krebs tricarboxylic acid cycle. In Darley-Usmar VM, Rickwood D, Wilson MT (eds), Mitochondria: a practical approach. London, IRL Press, pp 153-170

Rodrigo J, Springall DR, Uttenthal LO, Bentura ML, AbadiaMolina F, Riveros-Moreno V, Martinez-Murillo R, Polak J, Moncada S (1994): Localization of nitric oxide synthase in the adult rat brain. Phil Trans R Soc Lond B 345:175-221

Salter M, Duffy C, Garthwaite J, Strijbos PJ (1996): Ex vivo measurement of brain tissue nitrite and nitrate accurately reflects nitric oxide synthase activity in vivo. J Neurochem 66:1683-1690

Sapolsky R (1996): Why stress is bad for your brain. Science 273:749-750

Sapolsky R, Uno H, Robert C, Finch C (1990): Hippocampal 
damage associated with prolonged glucocorticoid exposure in primates. J Neurosci 10:2897-2904

Sheline YI, Wang PW, Gado MH, Csernansky JG (1996): Hippocampal atrophy in recurrent major depression. Proc Natl Acad Sci USA 93:3908-3913

Shepherd D, Garland PB (1969): Citrate synthase from rat liver. Meth Enzymol 13:11-16

Shintani F, Nakaki T, Kanba S, Sato K, Yagi G, Shiozawa M, Aiso S, Kato R, Asai M (1995): Involvement of interleukin-1 in immobilization stress-induced increase in plasma adrenocorticotropic hormone and in release of hypothalamic monoamines in the rat. J Neurosci 15:1961-1970

Shu S, Ju G, Fan L (1988): The glucose oxidase-DAB-Nickel method in peroxidase histochemistry of the nervous system. Neurosci Lett 85:169-171
Southan GJ, Szabo C (1996): Selective pharmacological inhibition of distinct nitric oxide synthase isoforms. Biochem Pharmacol 51:383-394

Telner JI, Singhal RL (1984): Psychiatric progress: the learned helplessness model of depression. J Psychiatr Res 18:207-215

Uttenthal LO, Alonso D, Fernández AP, Campbell RO, Moro MA, Leza JC, Lizasoain I, Esteban FJ, Barroso JB, Valderrama R, Pedrosa JA, Peinado MA, Serrano J, Richart A, Bentura Ml, Santacana M, Martínez-Murillo R, Rodrigo J (1998): Neuronal and inducible nitric oxide synthase and nitrotyrosine immunoreactivities in the cerebral cortex of the aging rat. Microscopy Res Tech 43:75-88

Wharton DC, Tzagoloff A (1967): Cytochrome oxidase from beef heart mitochondria. Methods Enzymol 10:245-250 